\title{
Influence of variety on total polyphenols content and antioxidant activity in apple fruits (Malus domestica Borkh.)
}

\author{
Veronika Valková*1,2, Hana Ďúranová1 ${ }^{1}$ Eva Ivanišová ${ }^{3}$, \\ Alexandra Kravárová4, Dagmar Hillová4 ${ }^{4}$ Lucia Gabríny ${ }^{1}$ \\ ${ }^{1}$ Slovak University of Agriculture in Nitra, Agrobiotech Research Centre, Slovakia \\ ${ }^{2}$ Slovak University of Agriculture in Nitra, Faculty of Horticulture and Landscape Engineering, Slovakia \\ ${ }^{3}$ Slovak University of Agriculture in Nitra, Faculty of Biotechnology and Food Sciences, Slovakia \\ ${ }^{4}$ Slovak University of Agriculture in Nitra, Botanical Garden, Slovakia
}

\begin{abstract}
ORCID
Veronika Valková: https://orcid.org/0000-0001-7048-6323

Hana Ďúranová: https://orcid.org/0000-0002-7274-6210

Eva Ivanišová: https://orcid.org/0000-0001-5193-2957

Hillová Dagmar: https://orcid.org/0000-0003-3209-9589
\end{abstract}

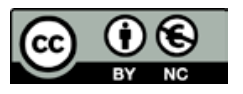

Article Details:

Received: 2021-07-01

Accepted: 2021-07-29

Available online: 2021-11-30

DOI: https://doi.org/10.15414/ainhlq.2021.0021

\begin{abstract}
Recently, an increasing interest in fruits and vegetable eating has been noticed in particular through epidemiological and biochemical studies pointing to their health benefits for human health. Specifically, apples (Malus domestica Borkh.) are one of the most frequently consumed fruits. Therefore, the current study aimed to compare the total polyphenols content (TPC) and antioxidant activity (AA) of apple fruits from different columnar apple trees growing in experimental conditions. For this purpose, fruits of 7 apple cultivars obtained from the Botanic Garden (Slovak University of Agriculture, Slovakia; vegetative season 2019/2020) were analysed. Among them, four green-yellow cultivars: Golden Delicious, Granny Smith, Goldcats, Rondo; one green cultivar with red spots: Kordona; one red cultivar: Redcats, and one pink cultivar: Pompink, were used. Method using the Folin-Ciocalteu reagent was applied to quantify TPC, and radical scavenging activity of the samples was measured with 2,2-diphenyl-1-picrylhydrazyl (DPPH) radical scavengers. Total polyphenols content (mg GAE/g dry weight) ranged from $2.92 \pm 0.31$ (cv. Pompink) to $9.02 \pm 0.32$ (cv. Granny Smith), whereas statistically significant differences ( $p<0.05$ ) were recorded between all analysed cultivars except for Rondo $(5.07 \pm 0.44)$ and Kordona (4.18 \pm 0.35$)$ cultivars as compared to Redcats $(4.96 \pm 1.06)$ one. As with TPC, the lowest values for AA were observed in the Pompink cultivar $(35.03 \pm 3.49 \%)$ and, conversely, the highest ones in the cultivar Granny Smith (88.55 $\pm 4.25 \%)$. These results suggest that the values for TPC and AA in apple fruits are strongly influenced depending on the apple cultivars. From this aspect, upon achievement of this survey, and employing more samples, it will be possible to create a comprehensive overview of the antioxidant properties of apple fruits with the possibility of their application in the food industry to develop innovative products with added value.
\end{abstract}

Keywords: Malus domestica, cultivars, DPPH assay, Folin-Ciocalteau assay

\footnotetext{
*Corresponding Author: Veronika Valková, Slovak University of Agriculture in Nitra, Tr. Andreja Hlinku 2, 94976 Nitra, Slovakia $\triangle$ veronika.valkova@uniag.sk
} 


\section{Introduction}

Recently, there has been a growing interest in including fruits and vegetablesinthehumandiet, as many scientific papers have confirmed their beneficial effect on their health (Wolfe et al., 2003). Apples (Malus domestica Borkh.) are widely cultivated throughout the world for their well-known nutrition and refreshing taste (Moscetti et al., 2018), and they are a highly researched crop within the scientific community (Havryliuk and Kondratenko, 2019; Horčinová Sedláčková et al., 2020; Horčinová Sedláčková et al., 2021). These fruits are not consumed just fresh; approximately one-third of them are processed into various goods, from which beverages belong to the most popular (Candrawinata et al., 2012). Indeed, due to their rich phytochemical profile indicating their health-promoting action on the health of the consumers, intake of apples and apple juice/products is still increasing around the world (Hyson, 2011).

Apple fruits are the main dietary sources of antioxidants, in particular phenolic compounds (Tsao et al., 2005), of which mainly flavanols, flavonols, hydroxycinnamic acids, anthocyanins, and dihydrochalcones are the major polyphenolic groups (Łata et al., 2009). The presence of polyphenols has gained special attention in apples because of their association with an improved antioxidant activity (AA) related to their ability to scavenge free radicals (Kalinowska et al., 2014; Li et al., 2014). The strong AA of apples is of great importance for human health because it can prevent various chronic diseases (Boyer and Liu, 2004). Furthermore, the anticancer and antiviral potential of apple fruits has been revealed by many in vitro studies (Suárez et al., 2010; Jakobek et al., 2013).

Generally, the variations in the phenolic profile of apples depend on many factors, such as apple cultivar, growth period, growing season (Awad et al., 2000; Tsao et al., 2003), maturity, geographical location (Awad and Jager, 2002), storage conditions (Golding et al., 2001) and also processing parameters (Candrawinata et al., 2013).

Therefore, our study aimed to evaluate the total polyphenols content (TPC) and the AA in different apple cultivars, and thus to select the cultivars with the highest content of the valuable natural antioxidants for their application in the production of enrichment food products.

\section{Material and methodology}

\section{Plant material}

Plant material used in the current study included 7 apple cultivars grown under precisely defined the same experimental condition, i.e., Golden Delicious, Granny Smith, Goldcats and Rondo, Kordona, Redcats, and Pompink (Table 1), which were obtained from the Botanic Garden (Slovak University of Agriculture, Slovakia; vegetative season 2019/2020). The samples were harvested at the full maturity stage, and whole fruits without seeds were used for analyses.

\section{Chemicals}

All the chemicals were obtained from Reachem (Bratislava, Slovakia) and Sigma Aldrich (Saint-Louis, Missouri, USA) and used without further purification.

\section{Preparation of extracts}

Ethanolic extracts were prepared from apple tree fruit samples dried at $45^{\circ} \mathrm{C}$ for $24 \mathrm{~h}$ using a laboratory hot air dryer (Universal oven UF 160, Memmert GmbH + Co.KG, Büchenbach, Germany). For each extraction, $0.2 \mathrm{~g}$ of sample was extracted by $20 \mathrm{~mL}$ of $80 \%$ ethanol for $2 \mathrm{~h}$ and centrifuged at $4000 \times \mathrm{g}$ for $10 \mathrm{~min}$ in Rotofix 32A (Hettich, Spenge, Germany). The supernatants were used for measurement of total polyphenols content (TPC) and detection of antioxidant activity (AA).

Table 1 Characterization of studied cultivar samples.

\begin{tabular}{lcccc}
\hline Samples & Colour of peel & Planting year & Country of origin & Ripening period \\
\hline Goldes Delicious & green-yellow & 2003 & USA & late \\
Granny Smith & green-yellow & 2003 & Australia & late \\
Goldcats & green-yellow & 2014 & Germany & medium/late \\
Rondo & green-yellow & 2014 & Czechia & medium/late \\
Kordona & green with red spots & 2014 & Czechia & medium/late \\
Redcats & red & 2014 & Germany & medium \\
Pompink & pink & 2014 & Germany & medium/late \\
\hline
\end{tabular}




\section{Evaluation of total polyphenols content}

TPC was measured by the method of Valková et al. (2021) using the Folin-Ciocalteu reagent. In this case, $0.1 \mathrm{~mL}$ of apple extracts was mixed with $0.1 \mathrm{~mL}$ of FolinCiocalteu reagent, $1.0 \mathrm{ml}$ of $200 \mathrm{~g} / \mathrm{L}$ sodium carbonate, and $8.8 \mathrm{~mL}$ of distilled water. After $30 \mathrm{~min}$ in darkness, the absorbance at $700 \mathrm{~nm}$ was measured using Jenway 6405 UV/Vis spectrophotometer (Cole-Parmer, Stone, United Kingdom). Gallic acid was used as a standard, and the results were expressed in grams per kilogram of gallic acid equivalents (GAE) dry weight (dw).

\section{Evaluation of antioxidant activity}

AA of extract samples was measured using 2,2-diphenyl1-picrylhydrazyl(DPPH) radical according to previously described procedures (Valková et al., 2021). Volumes of $0.4 \mathrm{~mL}$ of apple extracts were added to $3.6 \mathrm{~mL}$ of DPPH solution ( $0.025 \mathrm{~g}$ DPPH in $100 \mathrm{~mL}$ ethanol). The absorbance of the reaction mixture at $515 \mathrm{~nm}$ was determined using a spectrophotometer (Jenway 6405 UV/Vis, Cole-Parmer, Stone, United Kingdom). The AA was calculated as a percentage (\%) and determined according to the following formula: $\mathrm{AA} \%=[\mathrm{A} 0$ $\mathrm{AAT}) / \mathrm{A} 0 \times 100]$; where $\mathrm{A} 0$ is the absorbance of the control reaction (DPPH radical); A1 is the absorbance of the tested sample. The AA values increased in the following manner: weak (0-29\%) < medium-strong (30-59\%) < strong ( $60 \%$ and more).

\section{Statistical analysis}

Data from all analyses, which were performed in triplicates, were statistically evaluated using Prism 8.0.1 (GraphPad Software, San Diego, California, USA). One Way analysis of variance (ANOVA) followed by Tukey's test was used to assess the significance of differences between the analysed groups of samples. The level of significance was set at $\mathrm{p}<0.05$.

\section{Results and discussion}

\section{Total polyphenols content of samples}

In general, spectrophotometric methods for the determination of total polyphenols have been widely used in fruit analysis, as well as in pomology (Ivanova et al., 2010). In our study, the TPC in apple cultivars was assessed using Folin-Ciocalteu assay, which allows the estimation of all flavonoids, anthocyanins, and nonflavonoid phenolic compounds, i.e., all phenolics present in the samples (Benvenuti et al., 2004). Our results showed that TPC in analysed fruit extracts ranged from $2.92 \pm 0.31$ (cv. Pompink) to $9.02 \pm 0.32 \mathrm{mg} \mathrm{GAE} / \mathrm{g}$ (cv. Granny Smith), with an average of $5.80 \pm 0.32 \mathrm{mg} \mathrm{GAE} / \mathrm{g}$
(Table 2). Thus, the presented data demonstrate that the green-yellow peel cultivar of apples had a higher average TPC ( $7.13 \pm 0.32 \mathrm{mg} \mathrm{GAE} / \mathrm{g})$ than the other cultivars suggesting a relationship between TPC content and the colour of apple peel. Interestingly, cultivars planted in 2003 with the late-ripening period (cvs. Golden Delicious and Granny Smith) had a significantly higher TPC content than other ones planted in 2014 with medium or medium-late ripening period. Indicating that both factors (planting year, ripening period) could also be associated with the TPC of cultivars. On the other hand, the country of origin does not seem to play a key role in the TPC between the cultivars. Moreover, statistically significant differences $(\mathrm{p}<0.05)$ were recorded between all analysed cultivars, except for Rondo (5.07 $\pm 0.44 \mathrm{mg} \mathrm{GAE} / \mathrm{g}$ ) and Kordona (4.18 $\pm 0.35 \mathrm{mg} \mathrm{GAE} / \mathrm{g}$ ) as compared to Redcats (4.96 $\pm 1.06 \mathrm{mg} \mathrm{GAE} / \mathrm{g}$ ).

Polyphenols are antioxidant ingredients present in apple fruits, and because of their free radical scavenging activities, they exert a beneficial impact on human health (Kschonsek et al., 2018). As a very good source of polyphenols, they are widely consumed and available in supermarkets worldwide throughout the year (Wojdyło et al., 2008). Moreover, polyphenols are also closely related to the flavor and colour of apple products, and their composition notably depends on the apple cultivars (Guo et al., 2013).

Regarding the Granny Smith cultivar, its TPC was estimated by Alberto et al. (2006) to be $6.80 \pm 0.15 \mathrm{mg} \mathrm{GAE} / \mathrm{g}$, which is a lower value as it was demonstrated by our result $(9.02 \pm 0.15 \mathrm{mg}$ GAE/g). Values for TPC in cv. Granny Smith were also evaluated in the researches by Lotito and Frei (2004), and Henríquez et al. (2010); however, the comparison between our finding and the published data could not be performed since the values for TPC were determined either by different methods or in different units. Further, the TPC of ethanolic extract obtained from our Golden Delicious (7.71 $\pm 0.27 \mathrm{mg} \mathrm{GAE} / \mathrm{g}$ ) was consistent with a previous report by Massias et al. (2015) showing the TPC of the methanolic extract of this cultivar being $7.92 \mathrm{mg} \mathrm{GAE} / \mathrm{g}$. In contrast, the study by Junjian et al. (2013) revealed that the TPC of such methanolic extract was only $2.98 \mathrm{mg} \mathrm{GAE} / \mathrm{g}$. We assume that these differences (between our and other studies) can be attributed to biological factors (i.e., genotype and cultivar), as well as edaphic and environmental (i.e., temperature, light intensity, stress) conditions, and agricultural practices (fertilization, mulch colour, early forcing, and planting date). In addition, the solubility of polyphenols also depends on 
Agrobiodivers Improv Nutr Health Life Qual, 5, 2021(2): 227-232

Table 2 Antioxidant activity and total content of polyphenols in samples of apple extracts

\begin{tabular}{lccc}
\hline Colour & Cultivars & TPC (mg GAE/g) & AA (\%) \\
\hline & Golden Delicious & $7.71 \pm 0.27 \mathrm{a}$ & $88.49 \pm 0.73 \mathrm{a}$ \\
Green-yellow & Granny Smith & $9.02 \pm 0.32 \mathrm{~b}$ & $88.55 \pm 4.25 \mathrm{ad}$ \\
& Goldcats & $6.73 \pm 0.26 \mathrm{c}$ & $65.66 \pm 1.66 \mathrm{~b}$ \\
Green with red spots & Rondo & $5.07 \pm 0.44 \mathrm{~d}$ & $61.92 \pm 4.74 \mathrm{~b}$ \\
Red & Kordona & $4.18 \pm 0.35 \mathrm{e}$ & $41.69 \pm 2.07 \mathrm{c}$ \\
Pink & Redcats & $4.96 \pm 1.06 \mathrm{def}$ & $84.38 \pm 1.31 \mathrm{~d}$ \\
\hline
\end{tabular}

Notes: means \pm standard deviation. Values in the same column with different letters are significantly different $(\mathrm{p}<0.05)$

the solvent used, the degree of polymerization of the phenolic compounds, and their interaction (Anttonen et al., 2006; Markowski and Plocharski, 2006; Mureşan et al., 2012; Zhang et al., 2016).

\section{Antioxidant activity of samples}

The AA of apple cultivars was measured by the DPPH method in which the colour changes from purple DPPH radical to reduced yellow diamagnetic 2-diphenyl-1picryl hydrazine are detected (Asale et al., 2021). The values for inhibition of DPPH (\%) in apple extracts are summarized in Table 2. Depending on apple cultivars, antioxidant DPPH capacity in measured samples ranged from $35.03 \pm 3.49$ (medium strong; cv. Pompink) to $88.55 \pm 4.25 \%$ (strong; cv. Granny Smith). Demonstrable differences $(\mathrm{p}<0.05)$ were recorded among all analysed cultivars, except for between Granny Smith, Golden Delicious, and Redcast extract samples. Considering of the peel colour, the AA of the samples increased in the following manner: $35.03 \pm 3.49 \%$ (pink cv.) $<41.69 \pm 2.07 \%$ (green with red spots cv.) $<76.16 \pm 14.36 \%$ (green-yellow cv.) < $84.38 \pm 1.31 \%$ (red cv.). A similar trend of the relationship between planting year and ripening period and TPC was also observed in the case of AA.

Being an important source of natural antioxidants, apples possess one of the highest levels of radical scavenging capacity from the most consumed fruits and vegetables (Chinnici et al., 2004). Similar to our findings (88.55 \pm 4.25 and $88.49 \pm 0.73 \%$, respectively), strong values for AA in the methanolic extracts of Granny Smith (92.71 $\pm 0.33 \%)$ and Golden Delicious $(70.73 \pm 1.49 \%)$ were detected by Asale et al. (2021). Moreover, our results showed that values for AA increased in proportion to their TPC. This fact was also confirmed by the studies of Loots et al. (2006), and Tsao et al. (2005) who reported a positive correlation between both parameters investigated.
The current research revealed that apple samples analysed contained a relatively high TPC and exerted good antioxidant properties. In this context, their consumption may reduce the prevalence of various diseases including cardiovascular disorders and cancer (Knekt et al., 1997; Reagan-Shaw et al., 2010), thereby having a beneficial effect on human health. Taking into account this aspect, the World Health Organization (WHO) recommends eating $400 \mathrm{~g}$ of fruits and vegetables per day (approx. 5 pieces) (Dhandevi and Jeewon, 2015). Hence, the consumption of apples and their incorporation into developed food products may be considered one of the appropriate tools for improving the global health of the human population.

\section{Conclusions}

The goal of this study was to screen the TPC and AA in ethanolic extracts from seven different Malus domestica cultivars. The obtained data clearly demonstrates that the TPC in extracts was cultivardependent ranging from $2.92 \pm 0.31$ (cv. Pompink) to $9.02 \pm 0.32 \mathrm{mg} \mathrm{GAE} / \mathrm{g}$ (cv. Granny Smith). In effect, the higher values for TPC were observed in green-yellow peel cv. of apples as compared to the other ones. Since growing experimental conditions were the same, our results suggested that TPC content is associated with the colour of apple peel, ripening period, and also the age of apple trees. Moreover, the analysed samples did not display uniform DPPH radical scavenging activity. Indeed, its values ranged, similar to TPC, from $35.03 \pm 3.49$ (cv. Pompink) to $88.55 \pm 4.25 \%$ (cv. Granny Smith). From the analysed set of cultivars, our results showed that cv. Granny Smith and cv. Golden Delicious seems to be the most suitable for consumption in the daily diet and the development of enrichment food products to improve human health. In effect, both aspects (high amount of TPC and AA strong values) can help to increase the presence of biologically active substances within human nutrition. 


\section{Conflicts of interest}

The authors declare no conflict of interest.

\section{Ethical statement}

This article does not contain any studies that would require an ethical statement.

\section{Funding}

This publication was supported by the Operational Program Integrated Infrastructure within the project: Demand-driven research for the sustainable and innovative food, Drive4SIFood 313011V336, co-financed by the European Regional Development Fund.

\section{References}

Alberto, M.R., Rinsdahl Canavosio, M.A., \& Manca De Nadra, M.C. (2006). Antimicrobial effect of polyphenols from apple skins on human bacterial pathogens. Electronic Journal of Biotechnology, 9(3). https://doi.org/10.2225/vol9-issue3-fulltext-1

Anttonen, M.J., Hoppula, K.I., Nestby, R., Verheul, M.J., \& Karjalainen, R.O. (2006). Influence of fertilization, mulch color, early forcing, fruit order, planting date, shading, growing environment, and genotype on the contents of selected phenolics in strawberry (Fragaria $\times$ ananassa Duch.) fruits. Journal of Agricultural and Food Chemistry, 54(7), 2614-2620.

https://doi.org/10.1021/if052947w

Asale, Y., Dessalegn, E., Assefa, D., \& Abdisa, M. (2021). Phytochemicals and antioxidant activity of different apple cultivars grown in South Ethiopia: case of the wolayta zone. International Journal of Food Properties, 24(1), 354-363.

https://doi.org/10.1080/10942912.2021.1885440

Awad, M.A., \& De Jager, A. (2002). Relationships between fruit nutrients and concentrations of flavonoids and chlorogenic acid in 'Elstar' apple skin. Scientia Horticulturae, 92(3-4), 265-276.

https://doi.org/10.1016/S0304-4238(01)00290-4

Awad, M.A., De Jager, A., \& Van Westing, L.M. (2000). Flavonoid and chlorogenic acid levels in apple fruit: characterisation of variation. Scientia Horticulturae, 83(3-4), p. 249-263.

https://doi.org/10.1016/S0304-4238(99)00124-7

Benvenuti, S., Pellati, F., Melegari, M.A., Bertelli, D. (2004). Polyphenols, anthocyanins, ascorbic acid, and radical scavenging activity of Rubus, Ribes, and Aronia. Journal of Food Science, 69(3), FCT164-FCT169. https://doi.org/10.1111/j.1365-2621.2004.tb13352.x

Boyer, J., \& Liu, R.H. (2004). Apple phytochemicals and their health benefits. Nutrition Journal, 3(1), 1-15. http://www.nutritionj.com/content/3/1/5

Candrawinata, V.I., Blades, B.L., Golding, J.B., Stathopoulos, C.E., \& Roach, P.D. (2012). Effect of clarification on the polyphenolic compound content and antioxidant activity of commercial apple juices. International Food Research Journal, 19(3), 1055-1061.

Candrawinata, V.I., Golding, J.B., Roach, P.D., \& Stathopoulos, C.E. (2013). From apple to juice - the fate of polyphenolic compounds. Food Reviews International, 29(3), 276293. https://doi.org/10.1080/87559129.2013.790049

Chinnici, F., Bendini, A., Gaiani, A., \& Riponi, C. (2004). Radical scavenging activities of peels and pulps from cv. Golden Delicious apples as related to their phenolic composition. Journal of Agricultural and Food Chemistry, 52(15), 4684-4689. https://doi.org/10.1021/jf049770a

Dhandevi, P.E.M., \& Jeewon, R. (2015). Fruit and vegetable intake: Benefits and progress of nutrition education interventions-narrative review article. Iranian Journal of Public Health, 44(10), 1309-1321.

Golding, J.B., Mcglasson, W.B., Wyllie, S.G., \& Leach, D.N. (2001). Fate of apple peel phenolics during cool storage. Journal of Agricultural and Food Chemistry, 49(5), 22832289. https://doi.org/10.1021/jf0015266

Guo, J., Yue, T., Yuan, Y., \& Wang, Y. (2013). Chemometric classification of apple juices according to variety and geographical origin based on polyphenolic profiles. Journal of Agricultural and Food Chemistry, 61(28), 6949-6963. https://doi.org/10.1021/if4011774

Havryliuk, O., \& Kondratenko, T. (2019). Specific of the assimilation surface of columnar apple-tree. Agrobiodiversity for Improving Nutrition, Health and Life Quality, 3(1), 57-65. https://doi.org/10.15414/ agrobiodiversity.2019.2585-8246.057-065

Henríquez, C., Almonacid, S., Chiffelle, I., Valenzuela, T., Araya, M., Cabezas, L., Simpson, R., \& Speisky, H. (2010). Determination of antioxidant capacity, total phenolic content and mineral composition of different fruit tissue of five apple cultivars grown in Chile. Chilean Journal of Agricultural Research, 70(4), 523-536.

Horčinová Sedláčková, V., Hulin, M., \& Brindza, J. (2020). Comparison of old and landraces varieties of the apple tree (Malus domestica Borkh) in the variability of some morphological characters of leaves and flowers. Agrobiodiversity for Improving Nutrition, Health and Life Quality, 4(1), 112-123.

https://doi.org/10.15414/agrobiodiversity.2020.2585-8246

Horčinová Sedláčková, V., Hulin, M., Vinogradova, Y., Goncharovska, I., \& Brindza, J. (2021). Comparison of old and local apple varieties and seedlings (Malus domestica Borkh.) in the variability of some morphological characters of fruits and seeds. Agrobiodiversity for Improving Nutrition, Health and Life Quality, 5(1), 5571. https://doi.org/10.15414/ainhlq.2021.0007

Hyson, D.A. (2011). A comprehensive review of apples and apple components and their relationship to human health. Advances in Nutrition, 2(5), 408-420.

https://doi.org/10.3945/an.111.000513

Ivanova, V., Stefova, M., \& Chinnici, F. (2010). Determination of the polyphenol contents in Macedonian grapes and wines by standardized spectrophotometric methods. Journal of the Serbian Chemical Society, 75(1), 45-59. https://doi.org/10.2298/ISC1001045I 
Jakobek, L., Garcia-Villalba, R., \& Tomas-Barberan, F.A. (2013). Polyphenolic characterization of old apple varieties from Southeastern European region. J. Food Compos. Anal., 31(2), 199-211.

https://doi.org/10.1016/j.jfca.2013.05.012

Junjian, R., Mingtao, F., Yahui, L., Guowei, L., Zhengyang, Z., \& Jun, L. (2013). Optimization of ultrasonic-assisted extraction of polyphenols from apple peel employing cellulase enzymolysis. International Journal of Food Science \& Technology, 48(5), 910-917. https://doi.org/10.1111/ijfs.12041

Kalinowska, M., Bielawska, A., Lewandowska-Siwkiewicz, H., Priebe, W., \& Lewandowski, W. (2014). Apples: Content of phenolic compounds vs. variety, part of apple and cultivation model, extraction of phenolic compounds, biological properties. Plant Physiology and Biochemistry, 84, 169-188.

https://doi.org/10.1016/j.plaphy.2014.09.006

Knekt, P., Järvinen, R., Seppänen, R., Heliövaara, M., Teppo, L., Pukkala, E., \& Aromaa, A. (1997). Dietary flavonoids and the risk of lung cancer and other malignant neoplasms. American Journal of Epidemiology, 146(3), 223-230. https://doi.org/10.1093/oxfordjournals.aje.a009257

Kschonsek, J., Wolfram, T., Stöckl, A., \& Böhm, V. (2018). Polyphenolic compounds analysis of old and new apple cultivars and contribution of polyphenolic profile to the in vitro antioxidant capacity. Antioxidants, 7(1), p. 20. https://doi.org/10.3390/antiox7010020

Łata, B., Trampczynska, A., \& Paczesna, J. (2009). Cultivar variation in apple peel and whole fruit phenolic composition. Scientia Horticulturae, 121(2), 176-181. https://doi.org/10.1016/j.scienta.2009.01.038

Li, A.N., Li, S., Zhang, Y.J., Xu, X.R., Chen, Y.M., \& Li, H.B. (2014). Resources and biological activities of natural polyphenols. Nutrients, 6(12), 6020-6047. https://doi.org/10.3390/nu6126020

Loots, D.T., Van Der Westhuizen, F.H., \& Jerling, J. (2006). Polyphenol composition and antioxidant activity of Keiapple (Dovyalis caffra) juice. Journal of Agricultural and Food Chemistry, 54(4), 1271-1276.

https://doi.org/10.1021/jf052697i

Lotito, S.B., \& Frei, B. (2004). Relevance of apple polyphenols as antioxidants in human plasma: contrasting in vitro and in vivo effects. Free Radical Biology and Medicine, 36(2), 201-211.

https://doi.org/10.1016/j.freeradbiomed.2003.10.005

Markowski, J., \& Plocharski, W. (2006). Determination of phenolic compounds in apples and processed apple products. Journal of Fruit and Ornamental Plant Research, 14(2), 133-142.

Massias, A., Boisard, S., Baccaunaud, M., Calderon, F.L., \& Subra-Paternault, P. (2015). Recovery of phenolics from apple peels using $\mathrm{CO}^{2+}$ ethanol extraction: kinetics and antioxidant activity of extracts. Journal of Supercritical Fluids, 98, 172-182.

https://doi.org/10.1016/j.supflu.2014.12.007
Moscetti, R., Raponi, F., Ferri, S., Colantoni, A., Monarca, D., \& Massantini, R. (2018). Real-time monitoring of organic apple (var. Gala) during hot-air drying using nearinfrared spectroscopy. Journal of Food Engineering, 222, 139-150. https://doi.org/10.1016/j.jfoodeng.2017.11.023

Mureșan, E.A., Muste, S., Borşa, A., Sconța, Z., Crainic, D., \& Mureşan, V. (2012). Total phenolic content changes during apple growth as a function of variety and fruit position in the crown. Journal of Agroalimentary Processes and Technologies, 18(4), 341-344.

Reagan-Shaw, S., Eggert, D., Mukhtar, H., \& Ahmad, N. (2010). Antiproliferative effects of apple peel extract against cancer cells. Nutrition and Cancer, 62(4), p. 517-524. https://doi.org/10.1080/01635580903441253

Suárez, B., Álvarez, Á.L., García, Y.D., Del Barrio, G., Lobo, A.P., \& Parra, F. (2010). Phenolic profiles, antioxidant activity and in vitro antiviral properties of apple pomace. Food Chemistry, 120(1), p. 339-342.

https://doi.org/10.1016/j.foodchem.2009.09.073

Tsao, R., Yang, R., Xie, S., Sockovie, E., \& Khanizadeh, S. (2005). Which polyphenolic compounds contribute to the total antioxidant activities of apple? Journal of Agricultural and Food Chemistry, 53(12), 4989-4995.

https://doi.org/10.1021/jf048289h

Tsao, R., Yang, R., Young, J. C., \& Zhu, H. (2003). Polyphenolic profiles in eight apple cultivars using high-performance liquid chromatography (HPLC). Journal of Agricultural and Food Chemistry, 51(21), 6347-6353. https://doi.org/10.1021/jf0346298

Valková, V., Ďúranová, H., Miškeje, M., Ivanišová, E., Gabriny, L., \& Kačániová, M. (2021). Physico-chemical, antioxidant and microbiological characteristics of bread supplemented with $1 \%$ grape seed micropowder. Journal of Food \& Nutrition Research, 60(1), 9-17.

Wojdyło, A., Oszmiański, J., \& Laskowski, P. (2008). Polyphenolic compounds and antioxidant activity of new and old apple varieties. Journal of Agricultural and Food Chemistry, 56(15), 6520-6530. https://doi.org/10.1021/if800510

Wolfe, K., Wu, X., \& Liu, R.H. (2003). Antioxidant activity of apple peels. Journal of Agricultural and Food Chemistry, 51(3), 609-614. https://doi.org/10.1021/if020782a

Zhang, T., Wei, X., Miao, Z., Hassan, H., Song, Y., \& Fan, M. (2016). Screening for antioxidant and antibacterial activities of phenolics from Golden Delicious apple pomace. Chemistry Central Journal, 10(1), 1-9. https://doi.org/10.1186/s13065-016-0195-7 